\title{
Microgreens: A New Specialty Crop ${ }^{1}$
}

\author{
Danielle D. Treadwell, Robert Hochmuth, Linda Landrum, and Wanda Laughlin²
}

Frequently called "vegetable confetti," microgreens are young, tender greens that are used to enhance the color, texture, or flavor of salads, or to garnish a wide variety of main dishes (Figures 1 and 2). Harvested at the first true leaf stage and sold with the stem, cotyledons (seed leaves), and first true leaves attached, they are among a variety of novel salad greens available on the market that are typically distinguished categorically by their size and age. Sprouts, microgreens, and baby greens are simply those greens harvested and consumed in an immature state. Based on size or age of salad crop categories, sprouts are the youngest and smallest, microgreens are slightly larger and older (usually 2 in. tall), and baby greens are the oldest and largest (usually 3-4 in. tall).

Both baby greens and microgreens lack any legal definition. The terms "baby greens" and "microgreens" are marketing terms used to describe their respective categories. Sprouts are germinated seeds and are typically consumed as an entire plant (root, seed, and shoot), depending on the species. For example, sprouts from almond, pumpkin, and peanut reportedly have a preferred flavor when harvested prior to root development. Sprouts are legally defined, and have additional regulations concerning their production and marketing due to their relatively high risk of microbial contamination compared to other greens. Growers interested in producing sprouts for sale need to be aware of the risks and precautions summarized in the FDA publication Draft Guidance for Industry: Reducing Microbial Food Safety Hazards in the Production of Seed for Sprouting (2019).

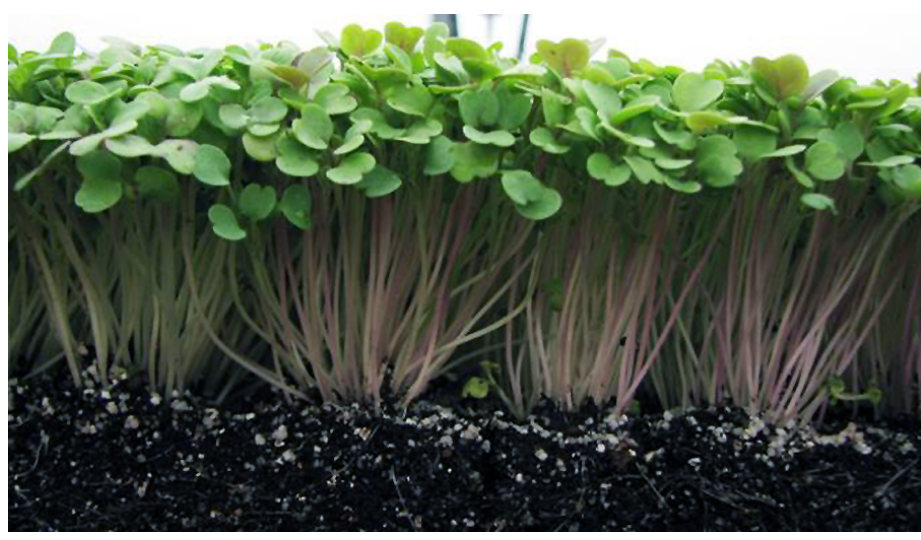

Figure 1. Microgreens in this photo are predominantly in the cotyledon stage and are a few days away from harvest. Credits: UF/IFAS

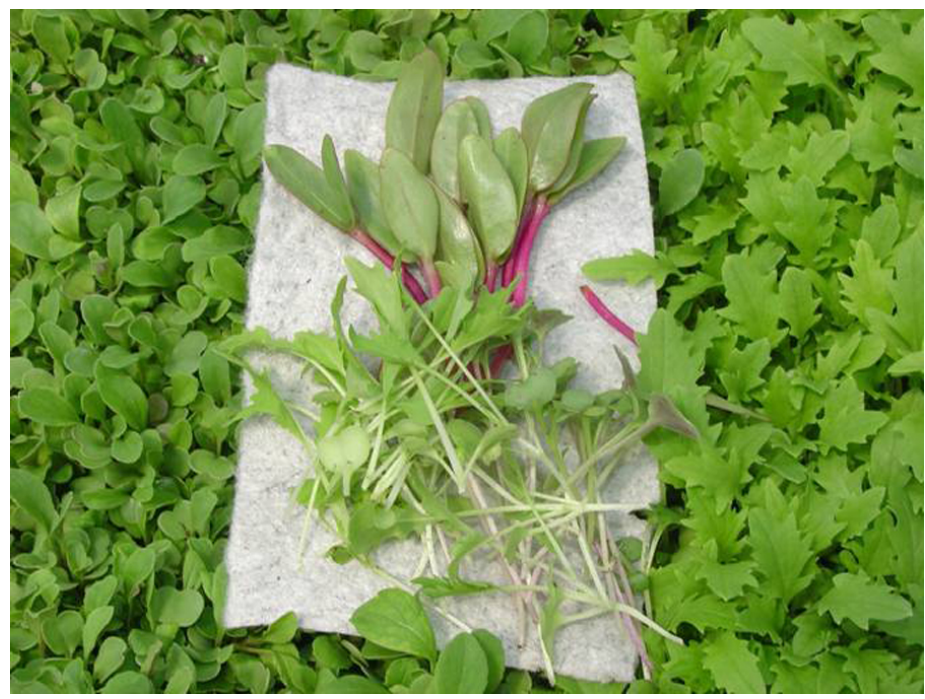

Figure 2. Microgreens are often termed "vegetable confetti." Credits: UF/IFAS

1. This document is HS1164, one of a series of the Horticultural Sciences Department, UF/IFAS Extension. Original publication date April 2010. Revised July 2013 and September 2020. Visit the EDIS website at https://edis.ifas.ufl.edu.

2. Danielle D. Treadwell, associate professor, Horticultural Sciences Department; Robert Hochmuth, regional specialized Extension agent and assistant center director; Linda Landrum, retired Extension agent IV; and Wanda Laughlin, greenhouse manager; UF/IFAS North Florida Research and Education Center-Suwannee Valley; UF/IFAS Extension, Gainesville, FL 32611.

The Institute of Food and Agricultural Sciences (IFAS) is an Equal Opportunity Institution authorized to provide research, educational information and other services

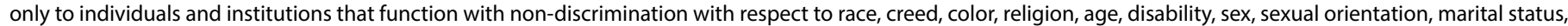

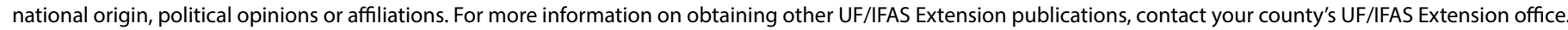
U.S. Department of Agriculture, UF/IFAS Extension Service, University of Florida, IFAS, Florida A \& M University Cooperative Extension Program, and Boards of County Commissioners Cooperating. Nick T. Place, dean for UF/IFAS Extension. 
The crops used for microgreens usually do not include lettuces because they are too delicate and wilt easily. The kinds of crops that are selected for production and sale as microgreens have value in terms of color (like red or purple), unique textures, or distinct flavors. In fact, microgreens are often marketed as specialty mixes, such as "sweet," "mild," "colorful," or "spicy."

Certain crops of microgreens germinate easily and grow quickly. These include cabbage, beet, kale, kohlrabi, mizuna, mustard, radish, swiss chard, and amaranth. Soaking some seeds prior to sowing, such as beets, helps facilitate germination. As many as $80-100$ crops and crop varieties have reportedly been used as microgreens (Figure 3). Others that have been used include carrot, cress, arugula, basil, onion, chive, broccoli, fennel, lemongrass, popcorn, buckwheat, spinach, sweet pea, and celery. Growers should evaluate various crop varieties to determine their value as microgreens. Many seed companies are very knowledgeable about the crops and varieties to grow, and a number of them offer organic seed.

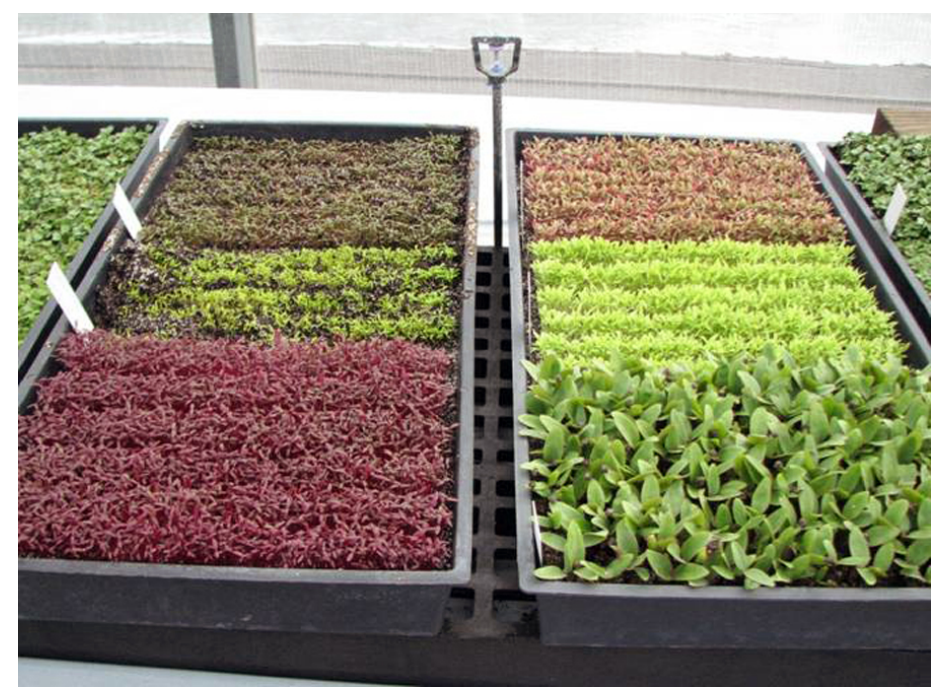

Figure 3. A variety of crops can be grown and sold as microgreens. Credits: UF/IFAS

The commercial marketing of microgreens is mainly targeted toward restaurant chefs or upscale grocery stores. Prices for microgreens generally range from $\$ 30$ to $\$ 50$ per pound. The product is packaged in plastic clamshell containers that are typically $4-8$ oz by weight but can be sold in $1 \mathrm{lb}$ containers as well.

\section{Production}

Microgreens may be grown by individuals for home use. Growing small quantities at home is relatively easy; however, growing and marketing high-quality microgreens commercially is much more difficult. Having the right mix at the perfect stage for harvest is one of the most critical production strategies for success. The time from seeding to harvest varies greatly from crop to crop. When seeding a mixture of crops in a single planting flat, growers should select crops that have a similar growth rate so the entire flat can be harvested at once. Alternatively, growers can seed the various crops singularly and mix them after harvest.

Microgreens can be grown in standard, sterile, loose, soilless germinating media. Many mixes have been used successfully with peat, vermiculite, perlite, coconut fiber, and others. Partially fill a tray with the medium of choice to a depth of $1 / 2$ in. to 1 or 2 in., depending on irrigation programs. Overhead mist irrigation is generally used only through the germination stage in these media systems. After germination, trays should be subirrigated to avoid excess moisture in the plant canopy.

An alternative production system uses one of several materials as a mat or lining to be placed in the bottom of a tray or longer trough. These materials are generally fiberlike and provide an excellent seeding bed. Materials may include burlap or a food-grade plastic specifically designed for microgreens, such as those made by Sure to Grow (Beachwood, OH). These mat systems are often used in a commercially available production system using wide NFT-type troughs. The burlap mat may be sufficient alone for certain crops or may require a light topping with a medium after seeding. Seeding may be done as a broadcast or in rows. Seeding density is difficult to recommend. Most growers indicate they want to seed as thickly as possible to maximize production, but not too thickly because crowding encourages elongated stems and increases the risk of disease. Most crops require little or no fertilizer, because the seed provides adequate nutrition for the young crop. Some longer-growing microgreen crops, such as micro carrot, dill, and celery, may benefit from a light fertilization applied to the tray bottom. Some of the faster-growing greens, such as mustard cress and chard, may also benefit from a light fertilization because they germinate quickly and exhaust their self-contained nutrient supply quickly. Light fertilization is best achieved by floating each tray of microgreens for 30 seconds in a prepared nutrient solution of approximately $80 \mathrm{ppm}$ nitrogen.

Microgreens are ready for harvest when they reach the first true leaf stage, usually at about 2 in. tall. Time from seeding to harvest can vary greatly by crop from 7 to 21 days. Production in small trays will likely require harvesting with scissors. This is a very time-consuming part of the production cycle and is often mentioned by growers as a major drawback. The seeding mat type of production system has gained popularity with many growers because it facilitates 
faster harvesting. The mats can be picked up by hand and held vertically while an electric knife or trimmer is used for harvesting, allowing cut microgreens to fall from the mat into a clean harvest container. Harvested microgreens are highly perishable and should be washed and cooled as quickly as possible. To improve quality, some chefs ask growers to deliver microgreens in the trays or mats so that they can cut the microgreens as needed. Wash the microgreens using good handling practices for food safety. Microgreens are usually packed in small, plastic clamshell packages and cooled to recommended temperatures for the crops in the mix.

\section{Reference}

Food and Drug Administration. 2019. Draft Guidance for Industry: Reducing Microbial Food Safety Hazards in the Production of Seed for Sprouting. https://www.fda.gov/ regulatory-information/search-fda-guidance-documents/ draft-guidance-industry-reducing-microbial-food-safetyhazards-production-seed-sprouting 